\title{
“O CISNE NEGRO”. DIREITOS, PODER E LIBERDADE DIANTE DO SILÊNCIO DA LEI. UM DEBATE TEÓRICO DA PRIMEIRA METADE DO SÉCULO XX ${ }^{1}$
}

\section{“THE BLACK SWAN”. RIGHTS, POWER AND FREEDOM IN THE FACE OF THE SILENCE OF THE LAW. A THEORETICAL DEBATE OF THE EARLY TWENTIETH CENTURY}

\author{
Alberto Spinosa ${ }^{2}$ \\ Università degli Studi della Tuscia (Viterbo, Itália) \\ Recebimento: 27 jul. 2020 \\ Aceitação: 13 ago. $2020^{3}$
}

\begin{abstract}
Como citar este trabalho / How to cite this work (informe a data atual de acesso / inform the current date of access):
SPINOSA, Alberto. "O cisne negro". Direitos, poder e liberdade diante do silêncio da lei. Um debate teórico da primeira metade do século XX. Revista da Faculdade de Direito UFPR, Curitiba, v. 65, n. 2, p. 217-227, maio/ago. 2020. ISSN 2236-7284. Disponível em: https://revistas.ufpr.br/direito/article/view/75465. Acesso em: 31 ago. 2020. DOI: http://dx.doi.org/10.5380/rfdufpr.v65i2.75465. Título original: «Il cigno nero». Diritti, potere e libertà di fronte al silenzio della legge. Un dibattito teorico di primo novecento. Inclui bibliografia.
\end{abstract}

\section{RESUMO}

Este artigo se ocupa da questão das "lacunas" da lei, na perspectiva da doutrina constitucional italiana. O que acontece quando a lei é silente e se está diante de um caso não previsto em lei? Durante o século XX, a questão das áreas não regulamentadas por lei e sua interpretação tornou-se o campo de batalha entre modelos de Estado liberal diferentes e opostos.

\section{PALAVRAS-CHAVE}

Áreas não regulamentadas. Liberdade. Soberania.

\section{ABSTRACT}

This paper focuses on the problem of "lacunae" in the law, from the perspective of Italian constitutional doctrine. What happens when the law is silent and when we are faced with a case not

1 O texto reproduz fielmente a intervenção ocorrida no XI Congresso Brasileiro de História do Direito “Estado, Direitos e Liberdades: em homenagem a António Manuel Hespanha” (Curitiba, 11-14 de novembro de 2019). Da comunicação oral, preferi manter o ritmo e a estrutura, de onde se percebe inclusive a opção de não sobrecarregar o texto com um excessivo aparato de notas. [N. do A.].

2 Pesquisador de Direito Internacional. E-mail: alberto.spinosa@unitus.it.

3 Este texto é uma tradução, elaborada pelo próprio autor para a Revista da Faculdade de Direito UFPR, do original publicado na revista Historia et ius - 1 agosto 2020 - DOI 10.32064/18.2020.12, disponível em https://bit.ly/3axvnvD. [N. do E.]. 
provided for by a legal disposition? During the Twentieth century, the issue of unregulated areas and their interpretation became the battlefield between different and opposing models of the liberal State.

\section{KEYWORDS}

Unregulated areas. Freedom. Sovereignty.

\section{1 “O CISNE NEGRO”}

O que acontece quando a lei silencia, quando nos encontramos diante de um vazio legislativo? Quando, em suma, o ordenamento jurídico do Estado apresenta uma lacuna? Atenuada no contexto dos ordenamentos constitucionais contemporâneos, a questão perde boa parte do seu caráter problemático. Num ambiente marcado pelo mais destacado pluralismo jurídico, como o das constituições democráticas do séc. XX, é inteiramente fisiológico, de fato, o ativar-se de um constante e cotidiano diálogo entre as diversas fontes do direito que desdramatiza o eventual silêncio da legislação. É emblemática nesse sentido a recente sentença da Corte Constitucional Italiana sobre o “fim da vida”, em matéria de suicídio assistido. Em face da obstinada inércia do legislador, a Corte se pronunciou fixando ela própria, à luz da Constituição, o critério da não punibilidade "de quem facilita a execução do propósito de suicídio [...] de um paciente mantido vivo por tratamentos de suporte vital e afeto diante de uma patologia irreversível” (REPUBBLICA ITALIANA, 2019, tradução nossa). Nenhum vazio jurídico, em suma, nenhuma lacuna. Ubi leges deficiunt (Onde a lei é deficiente) falam, pois, sempre os princípios constitucionais.

A questão se torna menos inócua, pelo contrário, no cenário do Estado de direito dos sécs. XIX e XX. Paolo Grossi (2001, p. 43 et seq.) nos ensinou: insensível a toda forma de pluralismo, o Estado moderno nasce sob o signo de um programa implacável de redução forçada da complexidade; programa que, no plano das fontes jurídicas, realiza-se com a identificação codicista entre Estado, direito e lei. O Código “é o direito positivo. E a sua última expressão é esta: o direito é a lei, porque fora da lei não é direito”, escreve Luigi Borsari (1871, p. 79, tradução nossa), um dos mais inteligentes comentadores do Código Civil Italiano de 1865. Mas se tudo está na lei, o que acontece quando falta a lei? É nessa conjuntura que a pergunta relativa ao que inicia onde termina a lei se alça a problema teórico de primeira grandeza. Se a legislação absorveu na sua esfera todo o universo jurídico, o que se vê olhando através de uma lacuna? O vazio, um espaço juridicamente neutro e asséptico, ou o vivo operar do direito extraestatal? Vê-se reemergir o pleno direito de liberdade do sujeito, finalmente desvinculado das amarras da legislação estatal, ou o vulto ameaçador (ou benévolo, conforme o gosto) da soberania? O poder criativo do juiz ou o poder discricionário da administração? Como um verdadeiro “cisne negro”, como o evento não previsto que faz em pedaços todo esquema 
interpretativo consolidado, a lacuna coloca o pensamento jurídico liberal diante dos próprios pressupostos e dos próprios limites, obrigando o jurista a tomar posição em face da 'crise' do mundo jurídico do séc. XIX.

No espaço que me é concedido, gostaria de tentar precisar algumas destas respostas, trazidas pelo debate jurídico italiano da primeira metade do séc. $\mathrm{XX}$, as quais correspondem, na passagem entre os dois séculos, a outras tantas declinações e transformações do Estado moderno.

\section{CÓDIGO E PARADIGMA SAVIGNIANO: O PRINCÍPIO DE AUTOSSUFICIÊNCIA DO SISTEMA CODICISTA}

O nosso interesse pelo tema das lacunas é, portanto - poderíamos dizer - constitucionalista, mas é pela reflexão civilista que convém iniciar. O porquê é evidente: pelo mundo do séc. XIX é o Código a verdadeira ‘constituição’ do Estado liberal, a sede dos princípios e dos valores fundantes da civilização burguesa. Ora, símbolo da completa legificação do ordenamento jurídico, o Código pretendeu a exclusividade, mas não explicou como tornar-se possível. Isso é, sem dúvida, verdadeiro para o Code Napoléon, mas também quando - como no caso italiano - o código invocou o socorro último aos “princípios gerais” (art. 3 disp. prel.), deixou, porém, inteiramente aberta tanto a questão relativa à sua proveniência quanto a relativa ao seu conteúdo. No final das contas, todo o debate interno às Escolas da Exegese europeias giraria em torno do problema (ao mesmo tempo teórico e prático) de como conciliar a aspiração do Código à exclusividade com a sua insustentável completude material.

Com um dos mais surpreendentes paradoxos históricos, quem ofereceria uma solução duradoura ao dilema seria justamente o principal adversário da codificação moderna: Savigny. Inútil empenhar-se para disciplinar tudo, todas as possíveis relações sociais. A vida real estará sempre um passo à frente e tornará constantemente vão todo esforço previdente da legislação. Existe, porém, uma segunda possibilidade. O trecho é conhecido e talvez nem seja necessário lê-lo:

Todavia, existe uma completude de outro gênero, que se pode ilustrar com um termo geométrico. Em todo triângulo existem certos dados de cuja relação derivam contemporânea e necessariamente todos os outros: o triângulo é dado por esses [dados], por exemplo, por dois lados e pelo ângulo respectivo. De maneira análoga, toda parte do nosso direito contém elementos a partir dos quais derivam os demais: podemos denominá-los de princípios fundamentais. Individualizar tais princípios e, a partir deles, perceber a íntima ligação e a relação que une todos os conceitos e os princípios jurídicos é tarefa entre as mais difíceis da nossa ciência, aliás, é justamente o que dá caráter científico ao nosso trabalho (SAVIGNY, 1982, p. 17, tradução nossa). 
Eis a solução oferecida por Savigny: é somente o Sistema da ciência que pode salvar o código de sua inevitável incompletude. Sem o sistema, o código é arruinado de saída. Para enfrentar a mudança histórica e a infinita variedade do real, o código deverá necessariamente desmentir a si mesmo recorrendo ora às fontes jurídicas que havia pretendido suprimir (primeira entre todas, a ciência do direito), ora à intervenção puntiforme e caótica da lei especial. Certamente, para Savigny esse era o motivo suficiente para abandonar ao seu destino a causa codicista. Se na ausência do sistema o código teria sido danoso, em sua presença teria sido inútil; portanto, somente cabia renunciar ao empreendimento - consideração contra a qual bradaria, em vão, Hegel (1987, p. 174175). Contudo, o paradigma savigniano e então pandectista da indefinida (ilimitada) capacidade de expansão lógica do sistema encontraria acolhida também em ambiente codicista, tornando-se especialmente na Itália - a estratégia prevalente de mediação e neutralização do conflito social.

Diante das transformações econômicas e sociais do final do séc. XIX, é para a racionalidade e autossuficiência jurídica do sistema-código que se olha como instrumento privilegiado de governo da mudança (CAZZETTA, 2002). Não convém trazer outras fontes jurídicas, nem almejar a intervenção ativa do legislador especial. O sistema do direito comum codicista não possui lacunas ou ao menos está em condições de integrar logicamente as próprias falhas, oferecendo assim às novas instâncias sociais uma solução fundada na racionalidade objetiva do direito dado. É translúcida a valência constitucional de semelhante estratégia. A tentativa é a de pôr freios e conter a esfera de decisão política dentro de limites rigorosos; o objetivo, em suma, de circunscrever ao máximo a possibilidade de legisladores e juízes de fazerem-se intérpretes autônomos e mediadores dos interesses sociais em jogo. O único árbitro legítimo do conflito é a ciência jurídica, a única em condições de oferecer uma mediação jurídica objetiva - pois fundada sobre o sistema dos conceitos e dos institutos do direito comum civilista - ao conflito entre os interesses sociais contrapostos, roubando oxigênio da discricionariedade (por natureza, instável e volúvel) das decisões políticas. Certamente, não se pode impedir inteiramente o legislador 'soberano' de permanecer em vigília. É, porém, sempre a ciência jurídica o sujeito titulado para fixar os critérios para sistematizar o ius novum, ou relegá-lo ao receptáculo conceitual do direito singular/excepcional, tornando-o inofensivo.

O início do debate em torno do problema das lacunas coincidiria com o anunciar-se do outono de tal equilíbrio constitucional. 


\section{LIBERDADE, SOBERANIA, PODER DISCRICIONÁRIO: DENTRO DO ABISMO DA LACUNA}

A cultura jurídica do séc. XIX, portanto, em larga medida apostou na capacidade do sistema civilista de bastar a si mesmo mediante a obra de incremento lógico das suas potencialidades normativas e por meio da função de gatekeeping que tal sistema exerce em relação à produção legislativa superveniente. Este durável 'pacto de não beligerância' entre ciência, jurisprudência e legislação se rompe, porém, de modo imprevisto diante do acentuar-se da 'questão social' e do incremento do intervencionismo público do novo Estado-providência. A descoberta de uma distância crescente entre a realidade social e a sua representação codicista abre novos espaços teóricos e convida a repensar novamente as regras do jogo.

Uma primeira estratégia é a jusliberal. A imagem de um direito positivo no qual as lacunas - como escreve Kantorowicz (1908, p. 82, tradução nossa) - “não são menos do que palavras” começa a sustentar uma estratégia de reavaliação do momento jurisprudencial que convida a identificar no juiz o sujeito mais idôneo para realizar esta nova e improrrogável obra de costura entre direito e vida. Na verdade, a estratégia não encontra grande acolhida na Itália. Ainda que a proposta contivesse em si o próprio limite, terminando por circunscrever o poder 'criativo' do juiz unicamente aos casos de lacuna, em vez de admiti-lo como dimensão natural de toda atividade hermenêutica - como faria o neoidealismo italiano (e pensemos em juristas da estatura de Giuseppe Maggiore, Max Ascoli e sobretudo Tullio Ascarelli) -, a receita jusliberal é percebida mais como uma provocação audaz do que uma concreta e realista alternativa teórica. Não faltam, todavia, juristas (pensemos em Pietro Cogliolo) que, ao denunciar o silêncio do Código em relação às novas demandas de justiça social (sobretudo em matéria de trabalho), identificam propriamente na sentença do juiz o lugar no qual as novas tendências democráticas e sociais podem encontrar cidadania, contornando de tal modo a rígida impostação individualista e as tendências conservadoras do sistema civilista do séc. XIX. Nenhum artigo do código, por exemplo, fixava os termos do aviso prévio em caso de demissão. A obrigação de distrato foi uma autêntica criação jurisprudencial advinda no silêncio da lei. Em suma, como a confirmar o velho provérbio, se a palavra era de prata, o silêncio se revelara de ouro:

\footnotetext{
Se alguém tomasse todas as sentenças que, de 1865 até hoje e especialmente as das últimas duas décadas, resolveram casos práticos com normas definidas não pela letra da lei, mas pelas normas que emergem da necessidade, formaria tantas páginas gloriosas que poderia realmente constituir o livro de ouro da magistratura italiana (COGLIOLO, 1913, p. 474, tradução nossa).
}

Não é, porém, a partir da reflexão civilista e filosófico-jurídica, mas sim a partir da reflexão juspublicista que no início do séc. XX aparecem as novidades teóricas mais desconcertantes. O que 
está em jogo é a construção do chamado Estado administrativo, ou seja, a conquista de uma lógica autenticamente publicista de intervenção do Estado no campo das relações privadas. São juristas como Oreste Ranelletti e Santi Romano que põem a questão sobre a mesa: convém superar o paradigma savigniano/pandectista, tendência que convidava a reconhecer no direito civil a estrutura portadora da sociedade liberal. Convém abandonar a ideia de que ao natural primado do direito comum civilista correspondesse o caráter meramente 'excepcional' do direito administrativo. Um modelo teórico que pode ter funcionado enquanto a intervenção pública no direito privado permaneceu esporádica, mas que não era mais sustentável diante da explosão das tarefas administrativas do Estado de fins do séc. XIX. Está em jogo, portanto, a busca da autonomia do direito administrativo e, mais em geral, a função e o papel do Estado em relação à sociedade. E, novamente, é em torno do problema da representação do espaço não regulado que se joga um dos jogos teóricos mais importantes.

Para Ranelletti, o ponto de partida não pode ser senão o Estado. A doutrina tradicional estava viciada por um erro individualista que era emendado (RANELLETTI, 1992). Ela movia-se a partir da ideia de que vinha primeiro o direito do sujeito e apenas num segundo momento o poder do Estado, mas as coisas estavam exatamente de modo oposto. O Estado é o prius em relação ao qual a liberdade do indivíduo é apenas o posterius. Não existe nenhuma anterioridade metafísica do indivíduo em relação ao Estado; ao contrário, é o Estado a subjetividade originária diante da qual o direito de liberdade individual se configura como mera criação da lei, como o efeito de uma determinação legislativa específica. Na ausência da lei, portanto, não se devia presumir a liberdade do sujeito, tutelada e protegida pelo primado do direito comum civilista, mas a soberania, o poder do Estado, a potestade da administração de intervir praeter legem para a persecução dos próprios fins e dos próprios interesses.

É precisamente contra tal perigo que para Donato Donati cabe afirmar o princípio da necessária completude de todo ordenamento jurídico. Na verdade, Donati combate simultaneamente contra três inimigos teóricos: a tradição civilista (e o seu princípio de expansão lógica do sistema); a heresia jusliberal (e a sua abertura em relação ao poder criativo da jurisprudência) e, por fim, os teóricos do Estado administrativo (e o primado que estes assinalavam ao poder discricionário da administração). Onde a lei cessa, não surge para Donati o vazio jurídico, um espaço livremente ocupado pelo poder criativo do juiz ou pelo poder discricionário da administração estatal, mas sim a liberdade originária do sujeito, ou seja, o direito do indivíduo de não suportar limites ulteriores à própria esfera de liberdade individual em relação àqueles que não estejam já expressamente previstos pela lei. Esta é, para Donati, a Grundnorm do Estado de direito dos sécs. XIX-XX: 
nós afirmamos que a partir do complexo das disposições particulares, as quais, 'prevendo' determinados casos, estabelecem para estes a existência de certas obrigações, vale dizer, de certas limitações, deriva uma norma geral deste conteúdo: em todos os outros casos não deverá haver qualquer limitação (DONATI, 1909, p. 35).

É, portanto, um retorno ao espírito de 1789 o que Donati deseja para sair da crise de fim de século. Um retorno àquele princípio de liberdade que desde a Declaração dos direitos do homem e do cidadão (art. 5) se impusera como a barreira portadora da experiência do Estado liberal de direito, o princípio com base no qual "tudo o que não é proibido pela lei não pode ser impedido, e ninguém pode ser obrigado a fazer aquilo que a lei não ordena”. Admitir a existência de casos não disciplinados pelo ordenamento e invocar o poder criativo do juiz significa fazer em pedaços o princípio de separação dos poderes; do mesmo modo, admitir a existência de zonas juridicamente vazias e o poder da administração de preenchê-las ao seu talante significa deixar o sujeito numa posição de incerteza em relação ao poder público. Permanece-se no interior da moldura do Estado de direito somente se, ao contrário, postula-se a existência de uma "norma geral exclusiva" como elemento central do ordenamento, a qual reafirme, além da lei, o princípio de liberdade individual como norma jurídica fundamental.

Mas se a liberdade é a norma, então a norma é a exceção. Não apenas, portanto, o direito público/administrativo, mas também o direito privado é - nessa perspectiva, enquanto limite à liberdade natural do sujeito - direito excepcional. Por isso não é admissível para Donati o princípio da expansão lógica e analógica nos casos em que a lei expressamente não o contemple. Enquanto derroga o princípio de liberdade, até mesmo o instrumento primeiro da hermenêutica jurídica se torna um inimigo potencial a ser confinado na esfera da exceção.

Nesse quadro, deve-se a Santi Romano a resposta culturalmente mais habilitada à tentativa de Donati de voltar ao liberalismo das origens e de negar, num certo sentido, as transformações do Estado moderno sobrevindas na virada do século. O ponto de partida para Romano é a ideia de limite: não há instituição, conquanto larga e abrangente, que sinta a necessidade de considerar relevantes todas as relações sociais. Limitação equivale a indiferença. Todo ordenamento é limitado porque se ocupa somente daquilo que considera interessante aos próprios fins, todo o resto caindo na irrelevância. Certamente, enquanto titular do poder soberano, o Estado, abstratamente falando, poderia considerar relevante aos próprios fins todo aspecto da vida social, até mesmo a esfera interior do sujeito. O que qualifica a experiência do Estado jurídico (ao qual Romano declara absoluta fidelidade) é, todavia, o fato histórico da renúncia a exercitar até o fim este poder. Não há direito sem limite. Se bem que a fins potencialmente ilimitados, “o direito de cada Estado é sempre limitado 
também no que concerne à sua matéria. O que quer dizer que há matérias que não entram no seu domínio, porque o Estado não se interessa por elas” (ROMANO, 2018, p. 170, tradução nossa).

É inadmissível, portanto, ver um verdadeiro direito de liberdade, juridicamente protegido, nas zonas não alcançadas pela lei (como sustenta Donati). O ordenamento limitado corresponde a uma esfera juridicamente irrelevante que pode ser sede não já de liberdades jurídicas, mas sim apenas de liberdade de fato. O que - note-se - para Santi Romano vale em ambos os sentidos: não se pode falar de liberdade do sujeito em relação ao Estado, nem tampouco do Estado em relação ao indivíduo. Entre o primeiro e o segundo não é possível nenhuma simetria: "Em relação aos submetidos não se é apenas livre, mas [...] se é senhor” (ROMANO, 2018, p. 172, tradução nossa). Certamente, dizer irrelevância não significa admitir o vazio jurídico absoluto, como sustenta Bergbohm (1892). Diante do princípio de pluralidade dos ordenamentos jurídicos, em suma, o que é irrelevante para o Estado não é dito que o seja também para outros ordenamentos. Do ponto de vista do Estado, as coisas, porém, não mudam: este poderá sempre legitimamente intervir em tal esfera, não apenas obviamente por meio do canal legislativo, mas também e mais frequentemente mediante a sua ação administrativa direta.

Entre a esfera do direito constitucional (o reino da soberania e das liberdades) e a do direito privado (mundo dos interesses patrimoniais), é, pois, novamente o direito administrativo, a atividade social do Estado, que para Santi Romano vem a impor-se como espaço autônomo de organização dos interesses. É a administração que poderá salvar o Estado da sua crise. Além dos limites intrínsecos da legislação estatal, é a administração que é chamada a interpretar e realizar o interesse geral, a oferecer - para além da mediação legislativa - o novo e mais idôneo terreno de composição do conflito social.

\section{PARA ALÉM DA LEI, A CONSTITUIÇÃO MATERIAL}

Na sua diversidade, as respostas oferecidas pela cultura jurídica dos sécs. XIX-XX à crise da legalidade moderna apoiavam-se sobre pressupostos implícitos comuns: a separação conceitual entre Estado e sociedade; a contraposição entre direito e política. Pode-se estar do lado do Estado para afirmar o seu primado e o seu poder de governo sobre a esfera dos interesses econômicos privados, ou advogar pela sociedade e trabalhar para preservar espaços de autonomia privada em 
relação às lógicas publicistas da ação administrativa. Mas o problema permanece o mesmo: como fazer conviver duas grandezas entre si incomensuráveis e separadas.

Pois bem, o advento do fascismo fará saltar este horizonte compartilhado, obrigando a redefinir os espaços de convivência entre dimensões (Estado, sociedade, direito, política, público, privado) cada vez mais entrelaçadas e misturadas entre si. Irene Stolzi já falou magistralmente sobre isso, portanto, só posso me limitar a não mais que mencionar o tema. Por um lado, temos uma parte da sociedade (o partido) que se faz (ou tende a se fazer) Estado, ocupando 'militarmente' todo espaço da esfera pública; por outro lado, temos um Estado que, à luz de uma ideologia política totalitária, pretende alcançar todo recôndito do social, replicando a si próprio até no foro interno do sujeito.

Nesse quadro, não é mais possível pensar em um espaço ‘imune’ à regulamentação. Não pode existir uma staatsfreie Sphäre (esfera livre do Estado), espaços que escapam ao direito positivo estatal porque a ele indiferente. Nem é mais sustentável a tese segundo a qual além dos vínculos legislativos se inicia o reino da liberdade individual. O ordenamento jurídico é privado de lacunas porque a ideologia fascista agora está preenchendo todos os espaços. Faltando o limite entre direito e política, é a ideologia política fascista que se impõe como critério supremo de unidade e de completude do ordenamento jurídico, como princípio orientador fundamental para a atuação dos juízes e administradores, muito além dos limites assinalados pelo tradicional princípio de legalidade do séc. XIX.

Como conciliar então as novidades da paisagem do séc. XX evitando que a transformação em curso se traduza definitivamente na vitória da hipótese totalitária, no primado absoluto da ideologia de partido? É nesse beco teórico que se coloca a reflexão de Costantino Mortati, com a qual se conclui idealmente o nosso percurso. A tentativa de Mortati é, como se sabe, a de fundar uma doutrina da constituição.

Em relação ao problema de onde encontrar o "critério supremo” (MORTATI, 1998, p. 9, tradução nossa) com base no qual se possa reconduzir à unidade uma dinâmica social que já largamente excede o campo da legislação positiva e não é mais domesticável por meio da fictio da soberania nacional, a resposta de Mortati é clara: a ordem é o fruto de uma luta constante pela “diferenciação”, é o resultado da batalha entre as forças organizadas para a afirmação de um rumo político fundamental. Esta é a ‘constituição material’ na qual o Estado e o direito positivo encontram (desde sempre) os seus princípios de unidade. Todo o percurso do Estado moderno pode ser reinterpretado à luz de uma sucessão entre fins políticos supremos que de quando em quando passaram seu testemunho e que de quando em quando forneceram os critérios fundamentais para 
integrar, desenvolver e completar - diante do ‘cisne negro’ do caso não previsto - o complexo normativo estatal.

Além dos limites e aquém da legislação não há nem a liberdade absoluta do sujeito, nem a soberania absoluta do Estado, mas a “constituição material” entendida como norma fundamental de caráter prescritivo, como endereço, como vetor em condições de orientar de baixo para cima todos os poderes públicos e privados, impulsionando-os à tarefa suprema da sua realização, de modo não diferente ao que ocorre no campo do direito canônico, lá onde o fim supremo da salus aeterna animarum (salvação eterna das almas) se coloca como princípio de unidade e coerência do sistema em condições de remediar os inevitáveis silêncios da legislação canônica. Certamente, Mortati escreve nos anos em que o endereçamento político fundamental corre o risco de coincidir, de fato, com a doutrina jurídica do regime. O fim da estação totalitária e o aportar da democracia constitucional fariam, todavia, justiça a um trabalho que superava a contingência do fascismo colocando-se - como escreveu limpidamente Fioravanti - sobre o plano mais profundo das transformações do Estado moderno.

Com a reflexão de Mortati chegamos, num certo sentido, ao ponto de partida, conseguindo entrever sob o pano de fundo o perfil do atual Estado constitucional. O problema das lacunas pode, portanto, finalmente sair do campo visual do jurista positivo e tornar-se, para todos os efeitos, objeto de reflexão historiográfica.

\section{REFERÊNCIAS}

BERGBOHM, Carl. Jurisprudenz Und Rechtsphilosophie: Kritische Abhandlungen. Lipsia: Denker \& Humblot, 1892.

BORSARI, Luigi. Commentario del Codice civile italiano. Torino: UTET, 1871.

CAZZETTA, Giovanni. Critiche sociali al Codice e crisi del modello ottoc entesco di unità del diritto. In: CAPPELLINI, Paolo; SORDI, Bernardo (org.). Codici. Una riflessione di fine millennio: Atti dell'incontro di studio (Firenze, 26-28 ottobre 2000). Milano: Giuffrè, 2002. p. 309-348.

COGLIOLO, Pietro. La tendenza democratica nella scienza e nella pratica del diritto civile [1910]. In: COGLIOLO, Pietro. Scritti varii di diritto privato. Torino: UTET, 1913. v. 1, p. 469-479.

DONATI, Donato. Il problema delle lacune dell'ordinamento giuridico. Modena: SEL, 1909.

GROSSI, Paolo. Mitologie giuridiche della modernità. Milano: Giuffrè, 2001. 
HEGEL, Georg Wilhelm Friedrich. Grundlinien der Philosophie des Rechts. Tradução Giuliano Marini, Lineamenti di filosofia del diritto. Diritto naturale e scienza dello Stato in compendio. Roma-Bari: Laterza, 1987.

KANTOROWICZ, Hermann. La lotta per la scienza del diritto. Milano: Arnaldo Forni Editore, 1908 [rist. Bologna 1988].

MORTATI, Costantino. La costituzione in senso materiale. Ristampa inalterata con una premessa di Gustavo Zagrebelsky. Milano: Giuffrè, 1998 [1940].

RANELLETTI, Oreste. Concetto e contenuto giuridico della libertà civile [1889]. In: Scritti giuridici scelti. Napoli: Jovene, 1992. v. 1. p. 189 et seq.

REPUBBLICA ITALIANA. Corte Costituzionale. Sentenza n. 242/2019. Giudizio: giudizio di legittimità costituzionale in via incidentale. Presidente: Lattanzi - Redattore: Modugno. Udienza Pubblica del 24/09/2019; Decisione del 25/09/2019. Deposito del 22/11/2019; Pubblicazione in G. U. 27/11/2019 n. 48. Norme impugnate: Art. 580 del codice penale. Atti decisi: ord. 43/2018.

ROMANO, Santi. L’ordinamento giuridico. Macerata: Quodlibet, 2018 [1918].

SAVIGNY, Friedrich Carl von, Vom Beruf unsrer Zeit für Gesetzgebung und Rechtswissenschaft. Heidelberg, Mohr und Zimmer, 1814. In: THIBAUT, Anton Friedrich Justus; SAVIGNY, Friedrich Carl von. La polemica sulla codificazione. Napoli: ESI, 1982. p. 87-197. 